\title{
Cultural Discount of Wushu in Cross-Cultural Communication
}

\begin{abstract}
Zhang Kun
Nanjing Polytechnic Institute 210048 Nanjing China

Email:565076790@qq.com

ABSTRACT

Based on literature study and other methods such as interview and logical analysis, a new concept and perspective which named "cultural discount" is used to interpretation the phenomena such as cultural distortion and cultural misreading of Wushu in cross-cultural communication. The cultural discount mainly due to following reasons. There are different cultural codes and aesthetic orientation between communicator and audience; Communication channels lack integration; Focus of content is not highlight etc; The strategies to avoid the cultural discount mainly include word replacement, building word power, integrating communication channels and establishing key content etc.
\end{abstract}

Keywords: Wushu, cross-cultural communication, cultural discount

\section{Preface}

Cross cultural communication refers to "information dissemination and cultural exchange activities among individuals, organizations or countries belonging to different cultural systems." The forms of cross-cultural communication include "international communication, intercultural communication, inter ethnic communication, inter ethnic communication and reverse communication" But in the context of Wushu communication, Wushu crosscultural communication focuses more on international communication. As one of the important cultural carriers in the international communication, Wushu is recognized as not a "simple body movement", but a "body culture form with implicit traditional culture" However, the profound traditional culture contained in Wushu can not help Wushu achieve the purpose of understanding, identification and acceptance in cross-cultural communication, it limits the accurate cognition and smooth communication of Wushu in western sports culture circle due to its profound culture. "Prosperous on the surface, desolate in the core" crosscultural communication of Wushu has not really taken root in the world. Wushu "is still not popularized in the world", and "the awareness rate and knowledge rate of Wushu in different countries are not high", which has seriously affected the realization of the expected value of Wushu communication. [1]

\section{Cultural discount and the phenomenon of cultural discount in the cross-cultural communication of Wushu}

\subsection{Cultural discount}

Cultural Discount, was first proposed by scholar Hillman Seelmann-Eggbert. In the context of general economics, cultural discount refers to "the reduction of the value of cultural products in the international market due to the difference of cultural background, which is not recognized or understood by the audiences in other regions." Due to cultural differences and other reasons, the audience lacks the cognition of the cultural background of the work, which makes it difficult to understand and identify the work, and leads to the phenomenon that the attraction of the heterogeneous cultural audience declines. In short, the difference of cultural structure is the main reason for the phenomenon of cultural discount. [2]

\subsection{Cultural discount in cross-cultural communication of Wushu}

In the cross-cultural communication of Wushu, there are also the phenomenon that the audience interprets the Wushu cultural code in terms of "devaluation" and "heterogeneity". [3] Therefore, this paper holds that the phenomenon of cultural discount in the cross-cultural communication of Wushu refers to the phenomenon that the specific cultural information expressed by Wushu does not have a strong sense of identity in the audience and not all of them are accepted, but only partially or wrongly accepted, that is, the phenomenon of cultural distortion and Cultural Misreading in the cross-cultural communication of Wushu. 

CROSS-CULTURAL COMMUNICATION OF WUSHU

\section{ANALYSIS ON THE PHENOMENON OF CULTURAL DISCOUNT IN THE CROSS-CULTURAL COMMUNICATION OF WUSHU}

\subsection{Cultural distortion in cross-cultural communication of Wushu}

The traditional Chinese culture creates a profound and flexible cultural atmosphere for martial arts, thus forming a unique subtle charm of martial arts. This charm can be demonstrated in the practice of Wushu routine, the explanation of Wushu theory and the name of Wushu action. However, this charm is most likely to cause cultural distortion due to cultural discount in cross-cultural communication. Especially in the translation of action names, it is very difficult to reflect the truth, which often leads to the complete disappearance of the aesthetic feeling of Wushu in the process of translation. [4] For example, Taijiquan has many action names such as "white crane light wings", "Gao Tan Ma", "hand waving Pipa" and so on. It vividly expresses the external form of martial arts, and has strong traditional cultural charm. However, in the book Tai Chi for beginners published in the UK, "play the guitar" is translated as "play the guitar". Such a translation is not only far from the action image expressed in the original, but also fails to fully convey the cultural charm of Wushu. It can be seen that inaccurate communication among key information audiences in the cross-cultural process of Wushu will inevitably produce certain discount for understanding and experiencing the charm of Wushu culture.

\subsection{Cultural misreading in the cross-cultural communication of Wushu}

There are several ways to translate Wushu in the process of external communication, for example, Wushu, China martial arts, China Gongfu, kungfu. Because these translated names come into being in different historical periods, they have different habits and ways of understanding in different countries. Therefore, many concept translations lead to some misunderstandings on the cognition of martial arts in foreign countries.

\subsection{Reasons for communicators}

Because the code of martial arts culture (such as terms) basically follows the traditional expression mode, has more words of ancient Chinese philosophy and literature, has strong metaphor and symbolism, and its semantics is vague they are not easy to understand in the national cultural background. However, in the cross-cultural communication of Wushu, there is a general lack of easy to identify cultural code, a lack of unified values and relatively concise discourse system, which is not conducive to cultural identity and acceptance, so that the actual effect of cross-cultural communication of Wushu is greatly reduced. [5]

\subsection{Audience reasons}

According to cultural relativists, culture has no advantages or disadvantages. For example, American anthropologist Ruth Benedict pointed out in his book "cultural model" that the formation of each culture has its own development context and historical background, as well as its existence rationality and unique value orientation. However, it is undeniable that the communication power of culture is different. Driven by the invisible hand of economy, there are strong and weak differences in the status and power of different cultures, so that different cultures show a single tilt state. Thus, the phenomenon of "Cultural Plateau and cultural basin" appears. Although cultural exchanges are two-way, it is difficult for a culture in a "basin" position to have equal dialogue power with a culture in a "Plateau" position. Because the dominant culture always controls the discourse power and makes the rules of the game. Those elite students of sports culture, especially western sports, with the mentality of cultural elite students, either look down on non western sports culture or ignore it. This not only makes the party in the weak position of cultural communication passive, but also increases the possibility of cultural discount.

\section{The avoidance of cultural discount in Wushu intercultural communication}

\subsection{Seek "cultural proximity" in expression and reduce language barriers through word placement}

In the cross-cultural communication of Wushu, the first thing to avoid the cultural discount lies in the translation, especially in the standardization of the translation of Wushu Terms. That is to say, in the process of translation, the first is the principle of purpose, and the second is the principle of 
coherence and the principle of faithfulness The translation of Wushu Culture loaded vocabulary should not be limited to the linguistic level, but to the "cultural approach", with the same or similar cultural symbols to reduce the rate of cultural discount. If we can't achieve cultural equivalence or similarity, we must try our best to find a way to achieve a certain cultural compensation effect and minimize the loss of cultural information. In a word, only when the cultural discount is reduced, the national is the world's.

\subsection{Building a discourse system with cultural differences}

Under the realistic background of cultural potential difference, it is the weapon and strategy of the weak to construct the discourse system. Wushu, as a heterogeneous culture in the western competitive culture atmosphere, is different from the western sports culture in both external form and internal spirit, which makes the western sports culture do not have the corresponding "topic" basis. Therefore, as a cross-cultural communication of martial arts against cultural differences, we need to further build a discourse system, so as to promote the deep integration with western sports culture from shallow integration to "multi win".

\section{CONCLUSION}

Martial arts cross-cultural communication is a process of trying to complete the accurate expression of cultural meaning in a strange context. Decoding in a heterogeneous cultural environment, cultural distortion and cultural misreading are inevitable, making cultural discount a more common phenomenon in cross-cultural communication.
Therefore, if we fully consider the phenomenon of cultural discount in this process, it will be more conducive to the spread of martial arts. Of course, to effectively avoid the cultural discount of Wushu cross-cultural communication is not to shallow or narrow Wushu culture, but to express Wushu culture more accurately in the process of crosscultural communication, and strive to achieve the effect of cultural appreciation.

\section{REFERENCES}

[1] Tong Bing. An analysis of misunderstandings in Intercultural Communication [J]. Journalism University, 2004 (3): 20

[2] Yan Weina. Research on the phenomenon of "cultural discount" in the cross-cultural communication of ethnic images [J]. Ethnic art research, 2014 (2): 39

[3] Chen Zhenyong, Guo Zhiyu. Concept of international communication and development of martial arts -interaction of body culture [J]. Journal of Shanghai Institute of physical education, 2005,29 (6): 52

[4] Wang Gang. The Enlightenment of Olympic world communication on the internationalization of Chinese Martial Arts [R]. Shanghai: Martial Arts Research Institute of General Administration of sport of China, martial arts branch of Chinese Academy of Sports Sciences, 2010

[5] Cixin. Martial arts bidding in attribute dilemma [n] China Youth Daily, September 2, 2013 (10) 